\title{
Estratégia: notas para uma abordagem econômica e histórica
}

\section{Enéas G. de Carvalho*1}

Resumo: O objetivo deste artigo é elaborar uma abordagem econômica e histórica da noção/conceito de estratégia. Mais especificamente, a intenção é propor uma definição de estratégia que ajude a desvencilhar este importante tópico de um emaranhado paralisante de escolas, abordagens e definições. Procurou-se, também, delimitar mais claramente a sua natureza e o quê pode (e o quê não deve) ser considerado como estratégia. Adicionalmente, buscou-se fazer uma avaliação crítica das principais taxonomias de estratégias. Para tanto, adotou-se basicamente uma perspectiva histórica e o enfoque proposto por Simon (1993) e, adicionalmente, procurou-se ampliá-lo e enriquecê-lo com as contribuições de vários outros autores relevantes.

\begin{abstract}
The purpose of this article is to elaborate an economic and historical approach to the notion/concept of strategy. More specifically, the intention is to propose a strategy definition that helps to unravel this important topic from a paralyzing tangle of schools, approaches, and definitions. Also, it was sought to delimit the nature of strategy more clearly and what can (and what should not) be considered as strategy. In addition, it was looked for to make a critical evaluation of the main strategy taxonomies. Therefore, it was adopted a historical perspective and the approach proposed by Simon (1993), and it was also search to expand and enrich the Simon's proposal with the contributions of several other relevant authors.
\end{abstract}

\section{Introdução}

Originário do âmbito militar (Mintzberg et al., 2006; Ancona, 1989b), o estudo da estratégia tem uma longuíssima tradição no campo da 'arte militar' (ver adiante) (Ancona, 1989a; Whittington, 2002) . Mais recentemente, a concepção de estratégia tem sido também tema de pesquisas e de reflexões nas ciências sociais. Nesta área, os administradores de empresas, principalmente, e os cientistas políticos têm se destacado na incorporação da noção às suas abordagens teóricas e às suas metodologias de pesquisa (Rumelt et al., 1991; Mintzberg et. al., 2000; Simon, 1986 e 1993; Lindblom, 1981; Braybrooke e Lindblom, 1972).

\footnotetext{
*Prof. do Departamento de Economia da UNESP/ Araraquara e pesquisador do GEEIN (grupo de estudos
} de economia industria). E-mail:egcarvalho58@gmail.com 
Tem se observado, também, a utilização da noção de estratégia por estudiosos de economia política internacional (EPI) (R. Gilpin, S. Strange, S. Ostry e L. Fiori), de relações internacionais (RI) (J. Nye Jr., K. Waltz) e de sociólogos como, por exemplo, T. Burns, J. Woodward e R. Aron (1986). Complementarmente, podem-se mencionar, ainda, alguns destacados historiadores econômicos e da tecnologia, como, por exemplo, A. Chandler, D. Hounshell, W. Lazonick, P. David e N. Rosenberg.

Diferentemente do que imaginou Marshall ${ }^{2}$, os economistas que o sucederam, especialmente os da corrente dominante, nunca deram maior atenção à noção (ou ao conceito) de estratégia. Uma exceção parcial, mas ainda assim digna de nota, foi a da teoria dos jogos, que adotou, entretanto, uma interpretação muito restritiva da noção de estratégia - que além de ser incompatível com a concepção mais usual da mesma, especialmente com a interpretação proposta por Clausewitz (2010)-, que se configurou mais como uma extensão particular da conhecida teoria da utilidade subjetiva esperada (USE) do que numa verdadeira introdução da noção de estratégia na teoria econômica (Simon, 1986 e 1993; Ancona, 1989a) (ver adiante).

Ao longo dos anos, um número relativamente reduzido de economistas, alguns de grande renome, se utilizou de forma mais ou menos explicita da noção/conceito de estratégia. Os exemplos mais conhecidos talvez sejam os de Marshall, Veblen,

Schumpeter, Morgenstern, Bain, Penrose, Hirschmann, Caves, Scherer, Porter e Perroux.

Mais recentemente, economistas como Freeman, Williamson, Nelson, Winter, Teece, Dunning, Langlois, Loasby, Foss, Krugman, Ghemawat, Kreps, Milgrom, Shapiro, Tirole, Pisano, Mowery, Cantwell, Dosi, Malerba e Morroni, entre outros, têm se juntado à lista dos estudiosos que incorporaram as estratégias aos seus temas de interesse e de pesquisa (Langlois, 2003; Rumelt et al., 1991; Pavitt e Steinmueller, 2002; Freeman e Soete, 1997; Loasby, 2010; Foss e Stieglitz, 2012). Deve-se destacar, entretanto, que, entre os economistas que têm dado importância a esta noção, a maior parte é de heterodoxos - alguns dos quais atuando profissionalmente em importantes escolas de business, como, por exemplo, M. Porter, D. Teece, D. Mowery e G. Pisano.

\section{Uma breve contextualização histórica}

\section{II.A. Antecedentes}

O interesse pela estratégia no âmbito da 'arte militar' remonta, pelo menos, ao $5^{\circ}$ século antes de Cristo. De fato, "[n]a China, por exemplo, já desde o século V a. C. que se elaboravam e experimentavam, de Confúcio a Wu Tse e Sun Tse, aqueles que se

\footnotetext{
${ }^{2}$ No Apêndice C ao Vol. II (da edição brasileira) dos Princípios de Economia, Marshall tratou com destaque da noção de estratégia. "Só recentemente, e em grande parte graças à influência salutar das críticas da Escola Histórica, foi dada preeminência, em Economia, a uma distinção correspondente à existente entre estratégia e tática na parte bélica" (Marshall Vol. II, 1985:353, ênfase acrescentada).
} 
tornariam (e permaneceriam durante séculos) os quatro princípios fundamentais da estratégia" (...) (Ancona, 1989a: 376). De outra parte, referências à oportunidade da utilização de estratégias podem ser também encontradas, na literatura ocidental, de Tucídides a Xenofonte e de (...) "Nícéforo Foca, passando por Frontino, Onosandro, o platônico, e pelo próprio Vegésio" (Ancona, 1989a: 376). O mesmo também pode ser dito de Maquiavel, em relação à sua Da Arte da Guerra (Ancona, 1989a).

A propósito, na tradição do classicismo grego, estratégia (strategia) "teria significado 'arte do estratego', e estratego, como estratégia, seriam derivados de stratos, equivalente a 'exército', e ago, equivalente a 'comandar', conduzir". (...) “[A] estratégia, como atividade expressa em estratagemas (stratagema), desde o início que tem vindo a ser apresentada como 'arte do engano', e isto aconteceu quer no âmbito da cultura ocidental quer no da cultura oriental (cf., por exemplo, A arte da Guerra de Sun Tse)" (Ancona, 1989a: 375).

Por sua vez, "tática (taktika) teria significado 'arte de dispor o exército', mas a palavra seria derivada de taktos, equivalente a 'ordenado' e a 'prescrito'. Não é por isso claro se a arte em questão devesse exprimir-se na imposição de comportamentos, ou manifestarse no âmbito de disposições recebidas"(...) “Entre 'estratego' e 'tático', evidentemente, a relação é de comandante a comandado, respectivamente”(...). (Ancona, 1989a: 375).

Mas a abordagem moderna da noção de estratégia da 'arte militar', bem como a sua separação da noção complementar de tática (ver a frente), só veio a se estabelecer de maneira mais clara, no século XIX, com a obra fundamental de Clausewitz (2010) - Da Guerra. No século XX, os principais expoentes deste debate no âmbito militar foram o general francês A. Beaufre, o capitão inglês L. Hart e o coronel norte-americano H. Summers (Ancona, 1989a; Mintzberg et al., 2000).

\section{II.B. A Formação de uma nova disciplina}

Fora do campo militar, os primeiros sinais de uma disciplina consistente -relacionada às estratégias de negócios e que ficou conhecida como strategic manegement- emergiram no âmbito da administração de empresas, com as publicações dos importantes livros do historiador de empresas A. Chandler (1962), do executivo da General Motors A. Sloan (1963) e do teórico da administração I. Ansoff (1965). Segundo Whittington (2002), estes três autores estabeleceram as fundações da abordagem clássica da estratégia na administração de empresas $^{3}$ (Rumelt et al., 1991; Langlois, 2003; Mintzberg et al., 2000).

Numa perspectiva mais abrangente (interdisciplinar), talvez não seja equivocado apontar também a contribuição de R. Aron ao debate da estratégia -com o seus

${ }^{3}$ Desta fase inicial, podem ser destacadas, ainda, as contribuições de P. Drucker, P. Selznick, K. Andrews, B. Henderson, T. Burns e G. Stalker. 
influentes livros Paz e Guerra entre as Nações (1986) e Pensar a Guerra, Clausewitz (vol. 2, 1976 e vol. 1, 1986)- como uma das mais amplas abordagens da segunda metade do último século.

Entretanto, da perspectiva adotada neste artigo, a principal contribuição à discussão da noção/conceito da estratégia foi elaborada pelo cientista político A. H. Simon. Muito embora não tenha escrito especificamente muito sobre estratégia, a participação de Simon - ganhador do prêmio Nobel de economia pelo seu trabalho original e importante para a área da chamada tomada de decisão (decision-making)- neste importante debate não deverá ser subestimada, em razão tanto da sua grande influência no plano mais geral do processo (teoria) de tomada de decisão, quanto da sua relevante contribuição (embora menos extensa e conhecida) à discussão da noção/conceito de estratégia especificamente (ver o subitem IV.B., abaixo).

Entre os grandes economistas, cabe destacar a tentativa de reforçar a utilização da noção de estratégia feita por Marshall nos Princípios e o seu uso, especialmente, no Industry and Trade ([1919]2015) (ver a nota $\mathrm{n}^{\circ}$ 1, acima) e, também, o emprego amplo da noção feito por Schumpeter em várias das suas obras: 1) Business cycles; 2) Capitalismo, socialismo e democracia; 3) History of economic analysis ;4) The economics and socilogy of capitalism (coletânea de artigos editada por R. Swedberg, em 1991); e 5) The nature and essence of economic theory ${ }^{4}$.

No caso de Marshall, deve ser enfatizado que, apenas no apêndice $\mathbf{C}$ dos Princípios -no interessante anexo sobre 'o âmbito e o método da economia'-, a abordagem da noção/conceito de estratégia revela uma preocupação de natureza metodológica/teórica. Curiosamente, as demais utilizações do termo feitas pelo grande autor inglês adotam um tom que sugere que o mesmo já tivesse sido incorporado ao vocabulário usual dos economistas (Marshall, ([1920], 1985) e ([1919], 2015).

Esta última qualificação parece se aplicar, tanto às três vezes empregadas no cap. XIII do Livro Sexto do V. 2 dos Princípios, quanto às outras nove vezes (pelo menos) em que utiliza a noção no Industry and trade. Este fato, talvez, se explique, pelo menos em parte, pela circunstância de que Marshall utiliza o termo, predominantemente, ao tratar do monopólio - em cujo âmbito específico (e restrito), o uso da referida noção já não era, de fato, incomum, depois da abordagem pioneira de Cournot (em 1838) -, especialmente no Industry and trade (Marshall, 1985 e 2015).

\footnotetext{
${ }^{4}$ Nas três primeiras obras de Schumpeter - que estão certamente entre as mais importantes do autor- a noção de estratégia aparece, pelo menos oito vezes no Business cycles (seis no V. 1 e duas no V. 2), ao menos dez vezes no Capitalismo, socialismo e democracia e pelo menos outras três vezes na History of economic analysis. Nos outros dois trabalhos mencionados, a noção foi utilizada pelo menos outras três e duas vezes, respectivamente.
} 
Já no caso do Schumpeter, deve ser destacado que - além do uso do termo ser mais frequente- o autor também atribui à noção de estratégia um papel bastante relevante. Em sua detalhada obra sobre o ciclo de negócios, ele afirma, por exemplo, que "[s]egredo com relação aos processos, patentes, diferenciação judiciosa de produtos, propaganda e similares, ocasionalmente agressão direta contra competidores reais ou potenciais, são instâncias de uma estratégia familiar (...)" (Schumpeter, V. 1 ([1939]2005): 107; ênfase acrescentada).

No seu mais influente livro, Capitalismo, socialismo e democracia, Schumpeter diz, a este respeito, que "[n]a primeira [na economia capitalista], são necessários infindáveis movimentos e contra-movimentos e as decisões devem ser tomadas numa atmosfera de incerteza que torna cego o fio da ação, enquanto aquela estratégia e aquela incerteza estariam ausentes da última [a economia socialista]" (Schumpeter, 1984: 248; ênfase adicionada).

Já na sua monumental History of economic analysis, ele declara que “(...) não importa quanto eliminemos de 'estratégia', permanece o fato de que este ajustamento produzirá resultados que diferem segundo o alcance do conhecimento, a rapidez da decisão e a 'racionalidade' dos agentes, e também segundo as diferentes expectativas que alimentam em relação ao curso futuro dos preços, isto sem mencionar o fato de que os agentes estão sujeitos a restrições adicionais provenientes de situações que criaram para si mesmos, por suas decisões passadas" (Schumpeter, 1994: 973; ênfase acrescida).

Não é surpresa, portanto, que Schumpeter seja considerado uma das principiais referências da chamada 'escola empreendedora' de estratégia - a vinculação estabelecida é entre o conceito de empresário (schumpeteriano) e a sua função, por um lado (Schumpeter, 1984, 1985 e 1968), e o papel do estrategista, por outro (Mintzberg et al. 2000; Mintzberg et al. 2006).

Mas é surpreendente, por outro lado, que a maior parte da literatura sobre estratégia não faça maiores referências à contribuição de Schumpeter, ao destaque dado por ele à noção de estratégia e a importante relação entre concorrência, inovação e estratégia que pode ser inferida da sua influente e criativa abordagem teórica (Schumpeter, 1984, 1985 e 2005; Freeman e Soete, 1997). É necessário reconhecer, entretanto, que, apesar de atribuir inegável relevância à noção de estratégia, o influente autor austríaco não se deu ao trabalho de discutir o seu significado e nem, ao menos, explicitar a sua concepção da mesma.

A existência de poucas referências na literatura especializada acerca da abordagem de Schumpeter ao tema da estratégia deve ser ainda mais enfatizada (e lamentada) no caso das contribuições dos economistas - algumas importantes exceções são encontradas entre autores que relacionam a competitividade internacional, as inovações e as estratégias (Teece et al., 1997; Rothwell, 1996; Freeman e Soete, 1997; Nelson, 2006; Morroni, 2006; Tidd et al., 2008; Melo et al., 2017).

Entre os economistas mais recentes, que abordaram a noção de estratégia, merecem ser destacados Nelson (2006), Langlois (2003), Teece (2007) e Freeman (Freeman e Soete, 1997). No primeiro caso, a referência decorre mais da importância atribuída pelo influente economista evolucionário à noção de estratégia do que à sua contribuição específica ao respectivo debate do tema. De fato, segundo Nelson (2006: 167), (...) 
"existem diferenças substantivas dentro de um ramo [industrial] e elas são significantemente importantes (...); e (...) essas diferenças são resultados de diferentes estratégias usadas para orientar a tomada de decisões em vários níveis das empresas (ênfase acrescentada).

No caso de Langlois (2003), o destaque se deve à sua contribuição relevante à discussão da noção/conceito de estratégia (Langlois e Robertson, 1995) (ver o subitem IV.A. abaixo). Com relação ao Teece, deve ser salientada a importante conexão, estabelecida por ele e colaboradores, entre a concepção de estratégia e a assim chamada abordagem das capacidades dinâmicas (dynamic capability) (Teece et al., 1997; Teece, 2007; Nelson, 2006; Tidd et al., 2008 ) (ver o subitem V.B., abaixo).

Por último, no caso de Freeman (Freeman e Soete, 1997), menção especial deve ser feita, em razão da elaboração - pelo emérito economista inglês e um dos fundadores da chamada escola neo-schumpeteriana ${ }^{5}$ de uma pioneira e ainda influente taxonomia de estratégias de inovação ${ }^{6}$ (ver, abaixo, o item VI). Esta contribuição de Freeman pode ser considerada como o ponto de partida de uma outra exceção parcial, mas não menos relevante, em relação ao comportamento dominante dos economistas (descrito anteriormente), que é encontrada no âmbito dos estudos relacionados às inovações, especialmente, às inovações tecnológicas.

Neste campo, os economistas (ou pelo menos alguns deles) parecem demonstrar um interesse maior pela noção de estratégia do que o fazem de uma maneira geral (Freeman e Soete, 1997; Nelson, 2006; Rosenberg, 1996 e 2006; Pavitt e Steinmueller, 2002; Tidd et al., 2008) ${ }^{7}$. De fato, a crescente importância atribuída às inovações e, especialmente, as inovações tecnológicas têm reforçado também o interesse pelo estudo e pela pesquisa das estratégias de inovação (e de tecnologias) não apenas pelos acadêmicos das áreas de business, de política científica e tecnológica, de historia econômica e da tecnologia, mas, também, por alguns economistas (Freeman e Soete, 1997; Pavitt e Steinmueller, 2002; Fargerberg et al. 2005; Nelson, 2006; Nelson e Winter, 2005; Tidd et al., 2008).

Como o processo de desenvolvimento e implementação de inovações - especialmente as tecnológicas- é caracterizado por elevado grau de incerteza - decorrente tanto da dimensão tecnológica quanto da dimensão econômica (Rosenberg, 1996; Freeman e Soete, 1997; Fagerberg et al., 2005; Nelson, 2006; Nelson e Winter, 2005) -, não é de surpreender que o estudo das inovações tenha como um dos subprodutos a abordagem paralela e complementar das estratégias de inovação (e tecnológicas) formuladas, implementadas e adaptadas pelas empresas sob condições de incerteza radical (Freeman

\footnotetext{
${ }^{5}$ Juntamente com os economistas norte-americanos R. Nelson e N. Rosenberg.

${ }^{6}$ Muito embora não realize uma discussão mais ampla sobre estratégias, Freeman, ao introduzir a sua taxonomia de estratégias inovativas, não se furtou a fazer algumas importantes considerações sobre o seu enfoque desta relevante questão (Freeman e Soete, 1997).

${ }^{7}$ Para um levantamento relativamente abrangente sobre a literatura de estratégias de inovação e de tecnologias, ver Pavitt, 1990; Pavitt e Steinmueller, 2002; Tidd et al., 2008.
} 
e Soete, 1997; Tidd et al., 2008; Pavitt, 1990; Pavitt e Steinmueller, 2002; Morroni, 2006).

Como já destacado, a noção de estratégia não tem despertado maior interesse entre os economistas -especialmente entre os pertencentes à corrente dominante-, não obstante alguns esforços localizados ${ }^{8}$ e até mesmo as contribuições de Marshall e, especialmente, de Schumpeter. É preciso reconhecer, entretanto, que os contributos de Marshall e de Schumpeter para utilização da noção de estratégia foram distintos, em boa medida, em razão das diferentes visões e perspectivas teóricas dos dois autores.

Nos termos do próprio Schumpeter, "[n]em Marshall, nem Wicksell, nem os clássicos viram que a concorrência perfeita é a exceção" (...). E, ainda, segundo o autor austríaco, (...) [m]as em vez de considerarmos os casos híbridos como desvios, ou adulterações, dos casos fundamentais, podemos também encarar os híbridos como fundamentais, e o monopólio puro e a concorrência perfeita como casos limites em que o conteúdo do comportamento real dos negócios têm sido refinado na direção errada" (Schumpeter, 1994: 975).

Em suma, Marshall usa o termo, principalmente, ao abordar o caso particular (e infrequente) do monopólio, enquanto Schumpeter emprega a noção ao enfocar, especialmente, o caso geral do oligopólio (Schumpeter, 1984, 1994 e 2005; Marshall, 1985 e 2015).

A inferência anterior parece ser reforçada pelo fato de não haver referência ao mencionado tópico nos índices remissivos, por exemplo, das representativas obras sobre a história do pensamento econômico de Schumpeter (1994) ${ }^{9}$, de Roncaglia (2005), de Blaug (1997), de Rima (2008) e de Hunt e Lautzenheiser (2011). Da mesma forma, o exame adicional das duas últimas edições do New Palgrave Dictionary of Economics (NPDE) (1987 e 2008) - inegavelmente o mais amplo e influente dicionário de economia - revela uma situação basicamente $\operatorname{similar}^{10}$.

\section{Tomada de decisão, estratégia e escolha}

\section{III.A. Tomada de decisão}

\footnotetext{
${ }^{8}$ E alguns outros já mencionados (ver, novamente, a introdução).

${ }^{9}$ Uma qualificação deve ser feita em relação History of economic analysis. Embora não exista referência ao termo estratégia no seu índice remissivo, o tópico aparece em pelo menos quatro passagens da infuente obra do autor austríaco (ps. 151, 972/ 973, 978 e 981), tendo sido uma delas citada acima (subitem II.B).

${ }^{10}$ Em tempo: na edição de 1987 do NPDE, por exemplo, há duas entradas para strategic como adjetivo e uma entrada strategy-proof como substantivo. Na última edição, de 2008, foram acrescentados três novos verbetes em que strategic aparece como adjetivo e um quarto em que strategy entra como substantivo (mixed strategy equilibrium). Infelizmente, nenhum deles aborda, entretanto, a noção de estratégia na perspectiva que foi adotado aqui e que procura, ademais, ser consistente com a concepção histórica do termo.
} 
No pensamento econômico dominante - no âmbito do que é conhecido como tomada de decisão (decision-making) ${ }^{11}$-, o que tem prevalecido é a abordagem normativa (ou prescritiva), com especial destaque para a influente teoria da utilidade subjetiva esperada - USE (ou $\boldsymbol{S E \boldsymbol { U }}$, em inglês). A teoria USE é (...) "um sofisticado modelo matemático de escolha que liga as fundações da maior parte da economia contemporânea, da estatística teórica e da pesquisa operacional. A teoria USE define as condições da perfeita racionalidade maximizadora de utilidades em um mundo de certeza ou em um mundo em que a distribuição de probabilidades de todos as variáveis relevantes pode ser fornecida pelos tomadores de decisão" (Simon, 1986: 2).

Em síntese, a teoria USE pressupõe que: 1) o tomador de decisão tenha uma função de utilidade bem definida e, portanto, seja capaz de estabelecer uma relação cardinal como unidade de medida de sua preferência com relação a um conjunto específico de eventos futuros; 2) o tomador de decisão poderá estipular à totalidade das séries futuras de eventos uma distribuição conjunta de probabilidades (objetiva ou subjetiva); 3) o tomador de decisão se confronta com grupo de possibilidades bem definido a partir do qual poderá fazer a sua escolha; e 4) o tomador de decisão optará (ou deveria optar) pela alternativa ou a escolha que maximize o valor esperado da sua função de utilidade - para o conjunto de eventos resultantes da sua escolha (Simon, 1989).

A teoria USE enfrenta, entretanto, sérias dificuldades sempre que, em economia, na política e em outros contextos sociais, ocorre interdependência/conflito de interesse real ou potencial, comportamento não coerente e, especialmente, se eles forem combinados com informação incompleta e incerteza (Simon, 1986 e 1989; Shackle, 1976; Sen, 1987).

"O estudo dos processos de decisões reais (...) revela um afastamento acentuado e inevitável do framework da teoria USE. (...) Crescentemente, a pesquisa está sendo direcionada para a tomada de decisão que adota uma descrição realista dos compromissos e aproximações que devem ser feitos com o objetivo de ajustar os problemas do mundo real aos limites informacionais e computacionais das pessoas e dos computadores, assim como às inconsistências dos seus valores e percepções" (Simon, 1986: 5 e 1981; Dosi e Egidi, 1991, Arthur, 1992; Morroni, 2006).

É digno de destaque que Popper (1975: 210), embora partindo de preocupações distintas, tenha chegado a uma conclusão bastante similar: "[o] que precisamos para compreender o comportamento humano racional (...) é algo de caráter intermediário entre o perfeito acaso e o perfeito determinismo - algo intermediário entre nuvens perfeitas [sistemas físicos imprevisíveis] e relógios perfeitos [sistemas físicos regulares]. (...) [P]ois, há, claramente, algo como conhecimento parcial, ou ignorância parcial" (ênfase acrescentada).

\footnotetext{
11 Também referida, muitas vezes, como teoria da decisão ou ainda como teoria comportamental da decisão (Vercielli, 1999; Mcfadden, 1998; Fishburn, 1987; Arthur, 1992).
} 
A teoria dos jogos, formulada na versão completa pelo matemático Von Neumann e pelo economista-matemático Morgenstern em 1944, foi, provavelmente, a tentativa mais ambiciosa de responder aquele tipo de questões colocadas à teoria USE (Simon, $1986 \mathrm{e}$ 1989). "Formalmente, um 'jogo' é qualquer interação que é governada por um conjunto de regras especificando as possíveis ações para cada participante e um conjunto de resultados para cada combinação de ações" (Heap, 1998: 205). E o enfoque característico da teoria dos jogos é assumir que: (1) os agentes têm pleno conhecimento destas regras; (2) eles são tipicamente racionais -isto é, suas preferências são compatíveis com os axiomas da teoria da escolha racional e, portanto, eles podem ser tratados como maximizadores de utilidades subjetivas esperadas-; (3) e eles têm conhecimento igual e comum da sua racionalidade e das regras do jogo.

Mas, como se sabe, as respostas fornecidas pela sofisticada teoria matemática dos jogos são por vezes enigmáticas e ambíguas. "Em muitas situações, nenhum curso de ação domina todos os outros; em vez disso, um conjunto inteiro de soluções possíveis é igualmente consistente com os postulados de racionalidade" (Simon, 1986: 7- 8; ênfase acrescentada).

\section{III.B. Escolhas e estratégias}

Neste contexto da teoria dos jogos, o termo estratégia foi (e é) utilizado numa acepção muito específica (e restritiva) - do ponto de vista destes autores- e que não é compatível com a maneira com que a noção tem sido habitualmente adotada no âmbito da 'arte militar', nas ciências sociais ou mesmo em grande parte das abordagens das estratégias de inovação. Na perspectiva de Neumann e Morgenstern a estratégia pode ser concebida da maneira que se segue.

"Imaginemos que cada jogador $k=1,2, . . n$, em vez de tomar uma decisão quando esta se revela necessária, reflita desde o início [sobre] todas as eventualidades concebíveis, isto é, que jogador $k$ comece a jogar segundo um plano completo: um plano que determine a escolha que ele fará em cada situação possível e por cada informação que tenha naquele momento, tendo em conta as normas de informação que as regras do jogo prevêem para aquele caso para cada jogador. Chamaremos estratégia a um plano semelhante" (Neumann e Morgenstern, 1947: 79, cit. por Ancona, 1989a; ênfase acrescentada).

De fato, nesta teoria matemática, estratégia é assimilada à escolha - não uma escolha qualquer, uma escolha com interdependência, na qual o agente "não tem conhecimento completo, pois não sabe o quê é que o seu oponente fará (...); [m] as sabe quais são as coisas que o seu oponente pode fazer" (Shackle, 1976: 183). Não se trata, portanto, de uma situação de escolha racional típica, uma vez que não há conhecimento completo.

Com efeito, como observou Shackle (1976: 183) argutamente, trata-se de uma circunstância de "escolha quase-racional de conduta": o agente não sabe exatamente o quê o oponente (ou os oponentes) fará (farão), mas tem conhecimento, supostamente, de 
todas as possibilidades de ação. Ou ainda, citando uma expressão feliz e muito esclarecedora de Georgescu-Roegen (1971:122), tratam-se de "situações onde o exato resultado não é conhecido, mas o resultado não representa uma novidade".

Já a acepção usual de estratégia não prescinde da existência de surpresa - “(...) o elemento mais poderoso e incisivo de toda a arte da guerra (...)" (Shackle, 1976: 183) -, ou da novidade e/ou do imprevisto (Ancona, 1989a). O reconhecimento da existência de afinidades importantes entre as concepções de novidade/surpresa de Schumpeter (1985 e 1968) e de Shackle (1976 e 1966) não é uma idéia inédita (ver, por exemplo, Davidson, 1996 e 1982-83 e Harvey e Metcalfe, 2005).

No presente caso, cabe destacar, entretanto, que "a resposta criadora" apontada por Schumpeter (1968) é um reforço considerável (e, talvez, surpreendente para alguns) à crítica incisiva de Shackle (1976 e 1966) à maximização da utilidade esperada e, portanto, à teoria dos jogos (ver, ainda, Simon, 1986 e 1993; Basili e Zappia, 2009). Por outro lado, é oportuno destacar, também, que as afinidades entre estes dois grandes autores parecem reforçar a interpretação de estratégia que tem sido defendida neste artigo (Simon, 1993; Schumpeter, 1968 e 1985; Shackle, 1976 e 1966; Davidson 1996 e 1982-83).

Ou ainda, dito de uma maneira mais atual e técnica, a estratégia supõe incerteza, informação incompleta, interdependência significativa e/ou inconsistência de comportamento dos agentes, que caracterizam, ao contrário do que imagina a maior parte dos economistas, as circunstâncias mais importantes e frequentes em que são tomadas as decisões humanas - não apenas as de natureza econômica (Simon, 1986 e 1993; Schakle, 1976 e 1966; Marroni, 2006; Lindblom, 1981).

Assim, se o futuro for conhecido - passível de previsão completa perfeita (ver a seguir)-, e a expectativa de determinado evento for certa, as escolhas concebíveis relativas ao referido futuro se reduziriam, na prática, a uma única - a hipotética escolha ("estratégia") maximizadora de utilidade e/ou de lucros (Morroni, 2006).

Previsão completa perfeita equivale à certeza e supõe, simultaneamente, um perfeito conhecimento a respeito dos resultados reais (conhecimento teórico) e uma completa habilidade de processamento de informações (HPI). Previsão completa imperfeita equivale a risco - estimação objetiva ou subjetiva das distribuições de probabilidades de todos os possíveis eventos; ela também supõe, como no caso anterior, completa (HPI) (Morroni, 2006).

Se a situação for de previsão completa imperfeita, a soma das probabilidades de todas as expectativas seria igual à unidade e haveria espaço para várias escolhas ("estratégias"), todas conhecidas, associadas aos diferentes riscos envolvidos (Morroni, 
2006; Shackle, 1976). A situação mudaria significativamente, também do ponto de vista das estratégias, se o futuro for passível de previsão incompleta - incerteza radical (impossibilidade de conhecer os eventos futuros) - e as expectativas a ele associadas não forem, portanto, certas.

Previsão incompleta resultaria, por sua vez, da incerteza substantiva - decorrente da combinação de um conhecimento incompleto da lista de possíveis eventos, devido a um futuro mutável, a uma completa habilidade de processamento de informação (HPI)- ou da incerteza de procedimento (procedural) - resultante da associação de um conhecimento completo da lista de eventos possíveis com uma incompleta (HPI) (Marroni, 2006).

Neste caso, a soma das expectativas - que podem ser consideradas como proposições acerca das probabilidades de que certos eventos futuros venham a acontecer - não seria igual à unidade e as estratégias concebíveis (e não as escolhas) seriam múltiplas e não se restringiriam apenas a eventos e a comportamentos (escolhas) conhecidos e/ou perfeitamente previsíveis (Shackle, 1976 e 1966; Morroni, 2006; Keynes, 1978; Davidson, 1996).

Ao contrário, as estratégias fariam face, nestes casos, à complexidade do ambiente, às incertezas, às novidades e às mudanças que um futuro imprevisível frequentemente pode trazer. As estratégias seriam, assim, formuladas, implementadas e adaptadas - sob condições de incerteza radical (substantiva e/ou procedimental) e, usualmente, modificadas à luz de novas informações e conhecimentos (Simon, 1986 e 1993; Shackle, 1976; Arthur, 1992; Morroni, 2006; Tidd et al., 2008).

Desse ponto de vista, elas poderiam ser qualificadas como estratégias no sentido estrito (e forte) do termo - e de forma compatível com a interpretação que habitualmente se atribuí a esta noção (como visto anteriormente)-, uma vez que seriam formuladas, implementadas e adaptadas sob condições de incerteza radical (Shackle, 1976; Morroni, 2006; Tidd et al., 2008).

Da perspectiva aqui proposta, as "estratégias" (escolhas) adotadas, sob condições de certeza ou de risco, devem ser consideradas no sentido não estrito (ou fraco) do termo, uma vez que, em tais circunstâncias, as "estratégias" (escolhas) não se defrontariam com surpresas, novidades ou mesmo com acontecimentos imprevistos (Shackle, 1976; Morroni, 2006).

Assim sendo, seria mais apropriado, talvez, chamá-las de escolhas sob condições de certeza (ou apenas escolha) - ou de escolhas sob condição de risco - e não de "estratégia", como fazem os economistas que adotam a teoria dos jogos como marco teórico. Segundo esta perspectiva, a denominação estratégia, no sentido forte (estrito) do 
termo, se aplicaria apenas às circunstâncias em que se observam incerteza radical, informação incompleta, interação significativa e/ou inconsistência de comportamento dos agentes (Simon, 1986 e 1993; Shackle, 1976 e 1966; Tidd et al., 2008).

Há uma clara convergência entre esta proposição adotada aqui e a argumentação desenvolvida por Shackle (1966) com respeito à distinção entre as noções de escolhas e de decisão. Vale lembrar que a semelhança em questão fica ainda mais clara quando destacamos que a definição de estratégia aqui apresentada (ver subitem IV.B., abaixo) considera, de acordo com Simon (1993), esta última como um sub-conjunto das decisões

\section{Principais características e uma tentativa de definição}

\section{IV.A. Principais características}

Apesar de já haver uma certa tradição de pesquisas nesta área nas escolas de administração de empresas -os estudos de administração estratégica tiveram início na década de 60 (Rumelt, et al., 1991; Whittington, 2002; Mintzberg, et al., 2006)-, ela não se traduziu em um consenso, ainda que relativo, quanto ao significado da noção de estratégia. No influente manual O Processo da Estratégia, Mintzberg et al. (2006:39) apontam, "a partir de uma pesquisa histórica sobre a literatura" (...), a existência de dez principais escolas dedicadas ao estudo da estratégia.

No mesmo livro são apresentadas, ainda, cinco distintas definições de estratégias definidas como sendo: 1) um plano, ou 2) um padrão, ou 3) uma posição ou 4) uma perspectiva ou, até mesmo, 5) um pretexto (Mintzberg et al. 2006; ver, também, Mintzberg et al., 2000) $)^{12}$

A título de exemplo, apresentam-se, a seguir, duas outras importantes definições de estratégia que não estão incluídas entre as cinco mencionadas anteriormente. A definição de Porter - provavelmente o autor mais influente entre os estudiosos de estratégia na área de administração de empresas- e a definição de Chandler, possivelmente uma das mais conhecidas e influentes entre os historiadores e os cientistas sociais - excluídos os administradores de empresas.

Segundo Porter, "[e]stratégia é criar ajustes entre as atividades de uma empresa. O sucesso de uma estratégia depende de fazer bem várias coisas -e não apenas algumas- e da integração entre elas. Se não houver ajuste entre as atividades, não há estratégia diferenciada e há pouca sustentabilidade” (Porter, 1996:75).

\footnotetext{
${ }^{12}$ No igualmente interessante livro de Whittington (2002), foram apresentadas, por outro lado, quatro grandes abordagens (ou teorias) de estratégias - 1) a clássica, 2) a evolucionária, 3) a processual e 4) a sistêmica -, que foram também caracterizadas sinteticamente, pelo autor, como sendo: 1) a racional, 2) a fatalista, 3) a pragmática e 4) a relativista, respectivamente (Whittington, 2002)
} 
Já segundo Chandler, "[e]stratégia pode ser definida como a determinação das metas e dos objetivos básicos de longo prazo de uma empresa, e a adoção dos cursos de ação e a alocação de recursos necessários para alcançar estas metas. Decisões de expandir o volume de atividades, de estabelecer plantas e escritórios distantes, de ingressar em novas funções econômicas, ou tornar-se diversificado ao longo de muitas linhas de negócios envolvendo a definição de novos objetivos básicos" (Chandler, 1991:13).

Tendo em vista este estado da arte pouco avançado no estudo das estratégias (à exceção, talvez, do âmbito militar), poderia parecer oportuno e, também, mais apropriado adotarse aqui um tipo de enfoque que tem sido utilizado em outras áreas - quando se aborda conceitos muito complexos e/ou polêmicos. São os casos, por exemplo, dos conceitos de vida, na biologia, e de tempo, na biologia e nas ciências sociais ${ }^{13}$. Nessas circunstâncias, em vez de se tentar definir os referidos conceitos complexos, tem-se optado por enfocar as suas características distintivas, as suas propriedades básicas, etc. (Mayr, 2008; Pomian, 1993).

Não obstante a falta de consenso mínimo quanto à definição, muitos estudiosos provavelmente concordariam que as principais características das estratégias são que elas: 1) afetam uma firma inteira ou, pelo menos, uma parcela significativa da mesma uma unidade estratégica de negócios, por exemplo-; 2) dizem respeito ao longo prazo, por natureza, e se baseiam mais nas concepções quanto ao futuro (previsões e expectativas $)^{14}$ do que em conhecimento sólido; 3) são atribuição dos administradores do mais alto nível da empresa ou, no mínimo, do nível divisional; 4) incluem o conjunto de objetivos e a escolhas de produtos e de serviços a oferecer; 5) abarcam a concepção e a configuração das políticas que determinam de que maneira a empresa se posiciona para a competição no mercado; 6) implicam na escolha de um escopo e de uma diversificação adequada; 7) envolvem a concepção do sistema administrativo, da estrutura organizacional e das políticas adotadas para coordenar e especificar o trabalho (Langlois e Robertson, 1995; Mintzberg et al. 2006). E “[é] a integração (ou o padrão de reforço) entre essas escolhas [decisões] que fazem do conjunto uma estratégia" (Rumelt et al. 1991: 6).

A propósito de síntese, parece ser possível destacar as avaliações quanto ao presente complexo e ao futuro incerto - e as respectivas expectativas ${ }^{15}$ e previsões a ele

\footnotetext{
${ }^{13}$ Este mesmo tipo de abordagem está sendo aventada aqui também, não tanto pela complexidade do conceito - certamente estratégia não tem o mesmo grau de complexidade do que os conceitos de vida e de tempo -, mas pelo fato de não haver ainda um consenso mínimo sobre a sua definição.

${ }^{14} \mathrm{~A}$ maneira de encarar o futuro, como sendo passível de previsão completa ou incompleta (Morroni, 2006), terá conseqüências cruciais tanto para a compreensão da noção de estratégia quanto para as suas conseqüências práticas (ver a seguir) (Tidd et al., 2008; Langlois, 2003).

15 "Alguns autores tomaram consciência do papel não periférico, senão central que demonstra a economia pelo tema da expectativa: (...) Marshall supôs que o homem de negócios, ao escolher a ação, é movido por aquilo que espera; Frank Knight contrastou o risco (que não é arriscado) com a incerteza (que sim é [arriscada]); Keynes acabou abrindo caminho através do racionalismo com crosta da teoria do
} 
associadas (Tidd et al., 2008; Shackle, 1976) - como sendo as características fundamentais das estratégias, entre as que habitualmente são apontadas como constitutivas das mesmas.

\section{IV.B. Uma tentativa de definição}

Não obstante as ponderações anteriores quanto à ausência de acordo em relação à noção/conceito de estratégia nas várias áreas e sub áreas em que ela tem sido discutida, talvez não seja um total desperdício de energia e de esforço procurar organizar as idéias, com vistas a tentar obter, quem sabe, algum avanço teórico e analítico neste âmbito. Talvez a dificuldade real possa ser contornada a partir de uma perspectiva teórica apropriada - não obstante o emaranhado de noções/definiçõos de estratégias, às vezes até conflitantes.

Tal perspectiva parece resultar, principalmente, das contribuições de Simon (1986, 1989 e 1993) no âmbito da chamada teoria da tomada de decisão (decision-making) em geral e, em especial, no campo mais específico da estratégia. "Embora os limites da racionalidade humana tenham sido enfatizados por alguns pesquisadores nos anos 1950, só recentemente tem havido extensiva atividade no campo da economia objetivando o desenvolvimento de teorias que assumem menos do que a escolha racional completa [plena] por parte dos administradores das empresas de negócios e de outros agentes econômicos" (Simon, 1986: 5) ${ }^{16}$.

De maneira assistemática, o tema da estratégia já havia sido tratado em algumas obras importantes deste influente cientista político norte-americano (Simon, 1965, 1981 e 1989). Contudo, foi só em um artigo -elaborado para um número especial da influente revista Strategic Management Journal- que Simon abordou a questão da estratégia de maneira direta e propôs uma definição nos seguintes termos: [e]stratégia, pode-se dizer, é a tomada de decisão (decision-making) que trata das grandes questões (Big Question)" (Simon, 1993: 131) ${ }^{17}$. Complementarmente, pode-se postular, então, que a estratégia é, segundo a perspectiva aqui adotada, o plano que estrutura e coordena as decisões estratégicas - isto é, as decisões relacionadas aos objetivos e/ou as metas principais das empresas (ou outras organizações), ou seja, as decisões relativas às grandes questões (Rumelt et al. 1991).

\footnotetext{
valor para chegar à noção de uma decisão de investir baseada nas sugestões fragmentadas das 'notícias'; e Myrdal sugeriu o recurso elementarmente brilhante de contrastar a expectativa de um intervalo por vir com o registro desse mesmo intervalo quando [ele] já tenha passado" (Shackle, 1976: 382).

16 Numa perspectiva semelhante, ver, também, Dosi e Egidi (1991); Popper (1975); Vercelli (1999); Morroni (2006).

17 Para abordagens compatíveis com este enfoque proposto por Simon, ver Nelson (2006); Freeman e Soete (1997); Pavitt (1990), Dosi e Malerba (1996), Langlois e Roberton (1995); Whittington (2002); Morroni (2006).
} 
Especificamente, a definição sugerida por Simon (1993) parece oferecer, do ponto de vista deste artigo, uma chave para retirar a noção/conceito de estratégia do aparente beco sem saída que a profusão de escolas, de abordagens e de definições tem provocado (Mintzberg et al., 2006; Mintzberg et al. 2000; Rumelt et al. 1991; Whittington, $2002)^{18}$.

Esta definição proposta por Simon (1993), além de não ser restritiva, coloca a estratégia no âmbito apropriado da teoria da tomada de decisão. Ao situá-la neste campo, Simon estabelece um diálogo crítico tanto com "[a] teoria formal clássica [normativa ou prescritiva] da tomada de decisão" (Simon, 1993:134; Fishburn, 1987) quanto com o "[c]onceito de comportamento racional"(Sen, 1987: 68; Popper, 1975) ${ }^{19}$, ao mesmo tempo em que contribui para acrescentar a ambos um maior realismo e relevância teórica (Simon, 1979, 1986 e 1993; Shackle, 1976 e 1966; Tversky e Kahneman, 1974; Kahneman, 2003; Morroni, 2006).

Deve ser destacado, ainda, que a abordagem da tomada de decisão descritiva (ou positiva) proposta por Simon e os seus colaboradores não se circunscreve apenas à dimensão teórica, incorporando também uma grande preocupação empírica. Com relação à atenção com a dimensão empírica, deve ser lembrado também, entre os colaboradores de Simon, o influente livro de Cyert e March (1992) (ver, a este respeito, Simon, 1979).

De maneira análoga, ao se referir aos resultados experimentais que apontam um número muito expressivo de irregularidades cognitivas nos processos de escolha e de percepção de informação (Tversky e Kahneman, 1974), Morroni (2006: 66) também salientou que: "[o]s trabalhos pioneiros relacionados às anomalias cognitivas na percepção e no processo de escolha que impedem a racionalidade total [plena] e a otimização foram realizadas conjuntamente por Daniel Kahneman, que foi premiado com o prêmio Nobel em 2002 e Amos Tversky, que morreu em 1996"20.

\footnotetext{
${ }^{18} \mathrm{Em}$ um interessante livro - que conta, ainda, com uma apresentação particularmente esclarecedora de O. E. Williamson-, Mahoney (2003) procurou mostrar, por outro lado, que os fundamentos econômicos da estratégia têm raízes em cinco distintas teorias da firma, a saber: 1) a teoria comportamental; 2) a teoria dos custos de transação; 3) a teoria dos direitos de propriedade; 4) a teoria da agência; e 5) a teoria baseada em recursos/capacidade dinâmica.

${ }^{19}$ Deve ser mencionado, também, que esta abordagem de Simon estabelece uma conexão importante com a teoria da resolução de problemas, originária da psicologia cognitiva, mas que tem recebido crescente atenção das áreas de inteligência artificial, da neurociência e de alguns economistas (Simon, 1979 e 1986; Dosi e Egidi, 1991; Tversky e Kahneman, 1974; Kahneman, 2003). Para uma abordagem sofisticada e equilibrada do enfoque tradicional, ver Arrow, 1987.

20"Entre os numerosos artigos destes dois autores, ver, por exemplo, Tversky e Kahneman (1974, pp. 3ff., 1992, pp. 44ff.); Kahneman e Tversky (1979, pp. 17ff., 1996, pp. 582ff.); Tversky e Fox (1995, pp. 93ff.); Kahneman (2003, pp. 1449ff.)" (Morroni, 2006: 66). A respeito da evidência experimental, Morroni (2006:66) faz referência a mais de uma dezena de autores e artigos.
} 
Na mesma linha, McFadden (1998) ${ }^{21}$ apontou pelo menos vinte e cinco irregularidades cognitivas -em um levantamento bem mais detalhado e extenso dos resultados experimentais $^{22}$ - que resultam na formulação de problemas de escolhas que são incompatíveis com a racionalidade perfeita [plena]. "Quando se observa o conjunto completo de estudos experimentais sobre cognição e escolha nos últimos vinte e cinco anos, o que se destaca é que os humanos falham consistentemente em obter e processar informações, e isto gera uma variedade de anomalias cognitivas (...). Eu concluo que a percepção racional falha, e que as falhas são sistemáticas, persistentes, generalizadas $e$ de grande em magnitude" (MacFadden, 1998: 28; ênfase acrescida).

Por outro lado, a definição de estratégia proposta por Simon (1993) é compatível com a maior parte das principais características que lhe são habitualmente atribuídas às estratégias (ver acima) (Langlois e Robertson, 1995; Mintzberg et al. 2000). Ao mesmo tempo, ela é, ainda, consistente com grande parte das pesquisas recentes relacionadas às estratégias de inovação e de tecnologia (Freeman e Soete, 1997; Tidd et al. , 2008; Pavitt, 1990; e Pavitt e Steinmueller, 2002).

Da mesma forma, ela é, igualmente, congruente com a interpretação que se consolidou no campo dos estudos militares (Ancona, 1989a e b; Clausewitz, 2010) e com várias abordagens influentes nas ciências sociais (Aron, 1986; Lindblom, 1981; Chandler, 1991). Com relação à influente definição de estratégia proposta por Chandler (1991), a compatibilidade não é total. De fato, a inclusão dos objetivos e das metas como parte das estratégias proposta na definição do emérito historiador de empresas norteamericano (ver acima) torna a mesma não inteiramente coincidente com a definição de Simon (1993), muito embora as semelhanças sejam, inegavelmente, significativas. De fato, como se sabe, para Simon (1986) os objetivos e as metas fazem parte do que tem sido chamado de problem-solving.

\section{Natureza e principais condicionantes}

\section{V.A. Natureza}

Quanto mais surpreendente, maior a possibilidade da estratégia ser bem sucedida. A novidade, a surpresa, a dissimulação e até mesmo o engodo parecem ser atributos desejáveis das estratégias bem sucedidas, não apenas no âmbito militar (Shackle, 1976, Ancona, 1989a e b; Whittington, 2002; Mitzberg et at., 2006).

\footnotetext{
${ }^{21}$ Que também foi laureado com o prêmio Nobel em 2000.

22 "Existem excelentes surveys da teoria de decisão comportamental [elaborados] por Camerer (1998), Machina (1989), Rabin (1997) e Thaler (1991); para reduzir a sobreposição, eu abreviei minha discussão às áreas da escolha sob incerteza e do comportamento nos jogos que são enfatizados nestes surveys" (McFadden, 1998:16).
} 
A estratégia parece ser um processo em três etapas - concepção, implementação e adaptação $^{23}$ (Morroni, 2006), até porque ela só tem sentido em condições de incerteza radical, informação incompleta, interação e/ou inconsistência dos agentes (ver o item III, acima). Como a estratégia diz respeito à tomada de decisões relacionadas às 'grandes questões' (Simon, 1993), parece mais apropriado considerá-la como sendo uma noção/conceito de longo prazo, devendo ser distinguida, portanto, da tática que, por sua vez, pode ser considerada como sendo de curto prazo. A distinção entre geral/muito importante e local/menos importante que habitualmente é feita entre estratégia e tática na 'arte militar' pode ser substituída, com vantagens, pela distinção entre longo (estratégia) e curto prazo (tática) em economia, até porque as decisões relativas ao longo prazo são, em geral, mais importantes do que as referentes ao curto prazo.

Com o intuito de esclarecer melhor a natureza das estratégias, uma outra distinção/qualificação -também relacionada de certa forma ao tempo (ver a nota 23 , abaixo)- pode ser feita entre as estratégias, conforme a concepção adotada neste artigo, e as decisões cruciais proposta originalmente por Shackle. "Para Shackle, um agente se engaja em uma decisão crucial quando 'a pessoa concernida não pode excluir da sua mente a possibilidade de que o simples de realizar o experimento pode destruir par sempre as circunstâncias em que' a escolha foi feita (Shackle, 1955, p. 6; cit. por Davidson, 1996: 493)".

Do ponto de vista aqui apresentado, nem toda decisão crucial -por exemplo, uma decisão rotineira de investimento- se configuraria como estratégia. Ou seja, as estratégias seriam apenas um subconjunto das decisões cruciais, uma vez que estas últimas não dizem respeito apenas às 'grandes questões' (Simon, 1993; Davidson, 1996 e 1982-83).

Muito embora exista uma inegável afinidade entre "o princípio da crucialidade" desenvolvido por Shackle (...) "para distinguir as situações envolvendo o tempo histórico, os mundos não ergódicos dos processos ergódicos"- (Davidson, 1982-83: 192; ênfase acrescentada) e as concepções de tomada de decisão sob incerteza e de estratégia adotada neste artigo, não será empreendida aqui, em razão da limitação de espaço, uma tentativa de comparação destas afinidades e diferenças, além da referência feita acima.

Por razões análogas, a dimensão temporal - caracterizada pela possibilidade de mudanças, de incerteza e de novidades - é incompatível com a tomada de decisão sob condições ditas de certeza e/ou de risco (Shackle, 1976). Esta situação parece exigir a introdução da tomada de decisão sob incerteza e, por extensão, da noção de estratégia, com relação às chamadas 'grandes questões' (Simon, 1993). Isto decorre, entre outras razões, da circunstância de que as pessoas, com frequência, são incoerentes em suas escolhas entre o presente e o futuro, como têm demonstrado as pesquisas sobre a

\footnotetext{
${ }^{23}$ Uma vez que o agente deve "estar preparad[o] "para adaptar sua estratégia em face de nova informação e conhecimento, que el[e] deve conscientemente buscar obter" (Tidd et al., 2008: 134).
} 
realidade da tomada de decisão (Tversky e Kahneman, 1974; Kahneman, 2003; McFadden, 1998; Simon, 1979 e 1986).

E o problema não tende a se atenuar, uma vez que as prioridades e os gostos dos seres humanos se modificam com a passagem do tempo. Como se sabe, a teoria USE assume, entre outros pressupostos, uma função de utilidade fixa e consistente (Simon, 1978, 1979, 1986 e 1989) (ver, novamente, o subitem III.A. acima), o que não é facilmente compatível com as mudanças nos gostos. Por outro lado, as teorias que postulam um limitado período de atenção não dispõem de meios que garantam a consistência das escolhas ao longo do tempo (Simon, 1986).

\section{V.B. Principais condicionantes ${ }^{24}$}

Tendo em vista que adotamos aqui a concepção de que as estratégias são um subconjunto da tomada de decisão -mais especificamente, as decisões atinentes às 'grandes questões'(Simon, 1993)-, parece razoável abordar a questão dos condicionantes principais das estratégias a partir do problema análogo dos condicionantes importantes da tomada de decisão.

Embora as abordagens da tomada de decisão tenham sido dominadas, inicialmente, pelo enfoque individual, atualmente a concepção que a tomada de decisão é de natureza coletiva/organizacional, pelo menos nos âmbitos das empresas e das entidades políticas, vem ganhando força (Vercelli, 1999; Simon, 1965, 1979 e 1981; Cyert e March, 1992; Morroni, 2006) - dado que estes agentes e/ou entidades são complexos (ou compósitos, conforme Simon, 1965: 232; Lindblom 1981).

No âmbito das organizações, parece haver um relativo consenso que os principais condicionantes da tomada de decisão incluem as relações hierárquicas; as estruturas de propriedade e, em especial, a atribuição de responsabilidades -particularmente para os envolvidos na tomada de decisão- e de direitos de controle; os objetivos das empresas; as regras e normas relativas às decisões coletivas; o grau de racionalidade do comportamento dos agentes - e as suas capacidades dinâmicas - e as respectivas motivações; e, também, a estrutura de incentivo dos stakeholders. Em organizações complexas (ou compósitas), estes componentes/participantes não estão, obviamente, isolados: ao contrário, eles estão interconectados mutua e fortemente (Morroni, 2006; Teece et al. 1997; Simon, 1965, 1979 e 1981; Cyert e March, 1992).

\footnotetext{
${ }^{24}$ Dado que não parece tarefa fácil (mesmo quando possível) estabelecer uma hierarquia clara entre os fatores envolvidos - cujo ranking parece ser, ademais, variável no tempo e setorialmente -, seria demasiado pretensioso e mesmo temerário postular (e defender) o status de determinantes aos fatores em exame. Talvez seja mais prudente e apropriado, portanto, chamá-los 'apenas' de condicionantes principais (importantes). Em tempo: deve ser mencionado que Morroni (2006) -uma das importantes referências bibliográficas deste subitem do artigo- também adotou um enfoque análogo. Como Morroni (2006) não explicita, entretanto, as razões que o levaram a adotar tal procedimento, só nos resta destacar o fato, conjecturando que as semelhanças nas abordagens, talvez, não tenham sido, apenas, mera coincidência.
} 
Como uma primeira aproximação útil, seria apropriado, talvez, resumir a cadeia causal da tomada de decisão (e das estratégias) nas organizações da seguinte forma: 1) A estrutura de propriedade condiciona/afeta os direitos de controle. 2) Estes últimos e a atribuição de responsabilidades desempenham um papel relevante na escolha das metas (ou objetivos) das firmas que, por sua vez, configuram, em certa medida, a respectiva estrutura de incentivos. 3) Esta última e o tipo de racionalidade -que esta estreitamente vinculado ao nível das capacidades dinâmicas (ver a seguir)- condicionam/afetam, por seu turno, o comportamento individual (e coletivo) no contexto do processo organizacional da tomada de decisão e, por extensão, da concepção, implementação e adaptação das estratégias (Morroni, 2006; Teece et al., 1997; Teece, 2007; Tidd et al., 2008).

$\mathrm{Na}$ realidade, o processo/as relações causais -descrito acima de forma bastante simplifica- revela-se bem mais complexo em razão dos inúmeros feedbaks que podem resultar (emergir) das relações, em várias direções, entre os diversos condicionantes principais do processo de tomada de decisão (e da adoção das estratégias) e, também, dos efeitos não negligenciáveis de vários outros fatores menos diretos e/ou imediatos (Morroni, 2006; Simon, 1979).

À semelhança de outras organizações sociais, as empresas são caracterizadas pela necessidade de poder e de controle. Poucos discordariam de que as estruturas de propriedade condicionam/afetam os direitos de controle que, por sua vez, influenciam de forma importante o processo de tomada de decisão (e as estratégias). Os determinantes da estrutura de propriedade e as relações entre a propriedade, o controle e a configuração organizacional são, muitas vezes, controversos e complexos e estão além do escopo e das restrições de espaço impostas a este artigo (Marroni, 2006).

As metas e as decisões - e, por extensão, as estratégias - das firmas são condicionadas pelas respectivas estruturas de incentivos que, por sua vez, estão fortemente relacionadas com as respectivas configurações organizacionais e de propriedade. As estruturas de incentivos são importantes condicionantes do processo evolutivo das organizações empresariais. Os comportamentos dos stakeholders das firmas são normalmente moldados por diversos tipos de incentivos e de sanções - dentre os quais se destacam: a) os estímulos e as penalizações dos mercados, 2) os incentivos relativos aos contratos entre partes independentes, 3) os estímulos relacionados às organizações reguladoras do funcionamento dos mercados e 4) os internos às próprias organizações empresariais (Morroni, 2006).

O tipo e o nível de racionalidade também são condicionantes de grande importância na configuração do processo de tomada de decisão - e na concepção, implementação e adaptação das estratégias - nas organizações. O tipo e o nível de racionalidade são baseados em capacidades (dinâmicas) no sentido de que os dois dependem do "hiato 
entre as habilidades [capacidades] ${ }^{25}$ dos agentes e da dificuldade do problema de decisão a ser resolvido" (Heiner, 1983: 562; Morroni, 2006).

O substantivo capacidades foi utilizado porque diz respeito ao papel central dos conhecimentos/aptidões organizacionais e administrativos -também referidos com frequência como strategic management- em integrar/coordenar, construir, adaptar e reconfigurar adequadamente as competências internas e externas das firmas - recursos e atributos organizacionais e funcionais - em resposta a um ambiente mutável (Teece et al., 1997; Teece, 2007; Nelson, 2006; Morroni, 2006;Tidd et al., 2008).

$\mathrm{O}$ adjetivo dinâmico foi empregado tanto para enfatizar as transformações do contexto econômico, quanto para destacar que as empresas -através dos processos de aprendizado- se tornam aptas a desenvolverem novos produtos, processos e até mesmo novas capacidades. Isto significa que as empresas não são passivas nos processos de mudanças - fazendo com que estas últimas devam ser consideradas, portanto, como parcialmente endógenas aos respectivos processos (Teece et al., 1997; Teece, 2007; Nelson, 2006; Morroni, 2006; Tidd et al., 2008; Schumpeter, 1968 e 1985).

As capacidades abarcam os processos organizacionais e administrativos e as posições atuais das empresas nos mercados. Os processos devem ser entendidos como as maneiras pelas quais a as coisas são feitas nas firmas, ou as 'rotinas' ou ainda os padrões de prática corrente. As posições dizem respeito à dotação corrente de ativos tecnológicos e de propriedade intelectual, à sua base de consumidores, às suas relações com fornecedores e distribuidores e às eventuais alianças estratégicas com competidores $^{26}$ (Teece et al. 1997; Teece, 2007; Nelson, 2006; Morroni, 2006; Tidd, 2008).

As capacidades dinâmicas são, por sua vez, o subconjunto das capacidades que permitem que as empresas, através dos processos de aprendizado, criem novos processos e produtos e, também, novas capacidades em resposta às condições mutáveis dos mercados. No limite, as capacidades dinâmicas podem viabilizar, até mesmo, as condições para a criação de novas trajetórias (econômicas e tecnológicas) para as firmas.

Por último, o subconjunto das capacidades dinâmicas que esta relacionado aos processos de aprendizados relativos à concepção, implementação e adaptação das estratégias pode ser chamado, por sua vez, de capacidades dinâmicas estratégicas ou, ainda, de meta capacidades dinâmicas (Teece et al., 1997; Teece, 2007; Nelson, 2006; Morroni, 2006; Tidd, 2008; Simon, 1993).

\footnotetext{
${ }^{25}$ Os termos habilidades e capacidades podem ser considerados, em certos contextos, como sinônimos. Optou-se aqui pela utilização de capacidades ao invés de habilidades porque o primeiro parece ser mais apropriado ao contexto coletivo em que as decisões (e as estratégias) são habitualmente tomadas nas empresas e o segundo parece mais adequado à tomada de decisão individual. Ver, a este respeito, Dosi e Egidi (1991) e Morroni (2006).

${ }^{26} \mathrm{Em}$ conjunto, os processos e as posições delimitam as trajetórias possíveis das firmas, isto é, as alternativas econômicas e tecnológicas disponíveis, bem como a atratividade das oportunidades futuras.
} 


\section{Taxonomias ${ }^{27}$}

Tendo em conta a diversidade de características/atributos presentes em vários âmbitos da economia como, por exemplo, a diversidade de capacidades/atributos dos agentes, de objetivos/valores/interesses e de comportamentos - múltiplas rotinas e estratégias (Simon, 1989, 1986; Teece et a.l, 1997; Teece, 2007; Nelson e Winter, 2005; Cyert e March, 1992; Morroni, 2006) -, parece oportuno que se adote nestas circunstâncias como tem sido feito em outras ares das ciências em que a diversidade é uma característica fundamental, particularmente na biologia ${ }^{28}$ (Mayr, 2008 e 2009; Ziman, 1996 e 2003) - uma abordagem que não prescinda do recurso às taxonomias/tipologias. Este parece ser o caso, também, do estudo das estratégias na economia.

Talvez não seja desnecessário lembrar que a utilidade potencial das taxonomias se baseia na capacidade das mesmas em auxiliar na formulação/concepção de hipóteses que, muito embora não sejam de aplicação geral, abarquem, ainda assim, uma quantidade considerável de eventos ou que retratem situações individuais de especial relevância Ademais, as taxonomias são muito úteis, por vezes indispensáveis, para organizar a diversidade (Schumpeter, 1994; Freeman e Soete, 1997; Reinert, 2016; Ziman, 1996 e 2003; Mayr, 2008 e 2009; Gould, 1987) ${ }^{29}$.

Por outro lado, como observaram Mitzberg et al. (2006), grande parte dos autores importantes, preocupados com as questões de conteúdo da chamada gestão estratégica, têm sua tipologia própria de estratégias habitualmente adotadas pelas diversas organizações, não considerando aqui as taxonomias equivalentes propostas pelos escritórios de consultoria. Talvez a mais conhecida das quais seja a derivada da matriz de crescimento-participação do BCG (Mitzberg et al. , 2000 e 2006; Whittington, 2002).

Provavelmente, as tipologias mais conhecidas e influentes foram àquelas propostas por Ansoff (1965) e, especialmente, por Porter (1980). Em 1965, Ansoff formulou uma classificação que se tornou bastante conhecida, baseada em quatro estratégias gerais: 1 )

\footnotetext{
27 Neste item, que não tem a intenção de ser exaustivo, serão abordadas apenas as taxonomias de estratégias elaboradas no âmbito acadêmico e não serão feitas, portanto, referências às tipologias criadas pelas consultorias especializadas (Mintzberg et al. 2006; Mintzberg et al. 2000; Whittington, 2002). Em tempo: estamos utilizando os termos taxonomias e tipologias como basicamente equivalentes.

${ }^{28} \mathrm{Em}$ cujo âmbito, a sistemática se constituiu numa disciplina de fundamental importância (Mayr, 2008 e 2009).

${ }^{29}$ De fato, como destacou muito apropriadamente o renomado físico inglês J. Ziman, “[n]a realidade, não se pode estabelecer uma teoria explicativa sem fazer referencia a uma taxonomia - ou seja, a uma classificação dos 'fatos' explicados. Isto ocorre, por exemplo, na análise newtoniana do movimento planetário, apoiado nas antigas distinções científicas entre estrelas fixas e planetas. Pelo contrário, uma taxonomia bem fundamentada muitas vezes atua como uma teoria preditiva, como mostrou Mendeleiev ao prever o descobrimento de novos elementos para preencher as lacunas de sua tabela periódica"(Ziman, 2003: 124).
} 
a penetração de mercado; 2) a diversificação; 3) o desenvolvimento de produto; e 4) o desenvolvimento de mercado. Uma década e meia depois, Porter desenvolveu uma taxonomia -que se constituiu, provavelmente, na mais influente e difundida de todasconcebida a partir de três estratégias genéricas: 1) a liderança de custos; 2) a diferenciação; e 3) o foco. Este último pode ser desdobrado, por sua vez, em 3a.) o foco em custo e em 3b.) o foco em diferenciação (Porter, 1980; Mintzberg et al., 2006).

Ainda que úteis e muito influentes, especialmente a tipologia de Porter, estas classificações são evidentemente excessivamente genéricas ${ }^{30}$ e, por isso, restritas em termos heurísticos (Nelson e Winter, 2005), face à elevada diversidade de estratégias empresariais existentes. Para colocar em perspectiva, pode-se citar a baste conhecida taxonomia de estratégias de inovação, elaborada por Freeman nos anos 70 (Freeman e Soete, 1997), que é constituída por seis casos, mas que comporta, claramente, outros desdobramentos adicionais (ver adiante).

Com um intuito de superar estas limitações óbvias, Mintzberg et al. (2006) propuseram uma tipologia com cinco grupos de estratégias: 1) localizar o negócio principal da empresa (n.p.e.); 2) diferenciar o n.p.e.; 3) elaborar o n.p.e.; 4) ampliar o n.p.e.; e 5) re-conceber o n.p.e.. Cada um destes cinco grupos de estratégias pode ser subdividido, por sua vez, em várias estratégias mais específicas, totalizando cerca de vinte e cinco casos.

Muito embora seja bem mais detalhada e, portanto, não incorrendo nas dificuldades acarretadas pelo excesso de generalidade das tipologias anteriores, esta classificação não escapa, entretanto, de outro problema sério: ela não faz referência direta às estratégias de inovação, em geral, e às estratégias tecnológicas, em particular, não obstante seja dado um relativo destaque ao papel das inovações e da tecnologia no livro de Mintzberg et al.(2006).

Antes de se tentar fazer uma avaliação mais assertiva sobre este último ponto, talvez seja apropriado efetuar-se a um breve comentário sobre as estratégias de inovações (e de tecnologia). Para os propósitos deste artigo (e tendo em conta a limitação de escopo e de espaço), parece ser suficiente tomar como exemplo a tipologia desenvolvida por Freeman. Originalmente elaborada nos anos 70, esta classificação é ainda uma das mais conhecidas e influentes neste campo e continua sendo muito útil (Freeman e Soete, 1997; Pavitt e Steinmueller, 2002; Pavitt, 1990; Nelson, 2006; Tidd et al. 2008).

\footnotetext{
${ }^{30}$ Tipologias igualmente muito genéricas também são encontradas no âmbito da 'arte militar'. Assim, se faz referências às estratégias ofensivas e defensivas e às estratégias de concentração e de dispersão (Ancona, 1989a). Mesmo no campo das estratégias de empresas, e em abordagens mais recentes, se faz uso de taxonomias ainda muito genéricas. Por exemplo, Tidd et al. (2008) classificam as estratégias das empresas como incrementalista ou racionalistas (a este respeito ver, também, Whittington, 2002).
} 
Nesta taxonomia das estratégias de inovação - que explicitamente não tem a pretensão de ser abrangente, pois se restringe apenas ao campo das inovações, e nem de ser exaustiva, mesmo neste âmbito mais restrito-, o emérito professor neo-schumpeteriano considerou seis casos (ou tipos ideais) de estratégias ${ }^{31}:$ 1) a ofensiva, 2) a defensiva, 3) a imitativa, 4) a dependente, 5) a tradicional e 6) a oportunista (ou de nicho) (Freeman e Soete, 1997).

De fato, não é difícil perceber que esta classificação comportaria várias inclusões e/ou adições. A título de exemplo, pode-se propor a combinação da tipologia de inovações de Freeman com a taxonomia das estratégias tecnológicas desenvolvida por Pavitt (1990) e/ou com o modelo de ciclo de vida das tecnologias proposto por Abernathy e Utterback (Utterback, 1996), e/ou, ainda, com a abordagem de Rothwell (1996: 40) do 'modelo de inovação dominante' 32 .

Estas eventuais combinações expandiriam o número de estratégias de inovação (e/ou tecnológicas) para um número maior, uma vez que elas introduzem as possibilidades de a) variações das estratégias ao longo do tempo e de b) combinações de mais de uma estratégia ao mesmo tempo - associadas ao fato de que as empresas, especialmente as grandes, são em geral multi-produtoras e/ou multi-tecnologias, e, muitas vezes, multimercados (Freeman e Soete, 1997; Rothwell, 1996; Marsili, 2001; Pavitt e Steinmueller, 2002).

Mas este não é o problema principal, muito pelo contrário. Mas, voltando agora à questão das tipologias de estratégias mais conhecidas, devemos reconhecer que - mesmo tendo reduzido o nível de generalidade ao aumentar significativamente o número de casos considerados - elas não escapam de outro problema bastante sério: deixam de abordar as crescentemente importantes estratégias de inovação (e de tecnologia). Um leitor menos exigente poderia argumentar, talvez com alguma razão, que o problema não seria tão grave - uma vez que sempre seria possível incorporar, por exemplo, as estratégias de inovação (e até mesmo as estratégias tecnológicas) à classificação, proposta por Mintzberg e colaboradores (Mintzberg et al., 2006).

Sem dúvida, esta seria a solução formalmente mais imediata e, provavelmente, a mais simples. Mas talvez não seja a mais apropriada. Com efeito, tendo em conta a centralidade do papel das inovações, em geral, e das inovações tecnológicas, em particular, para o desempenho bem-sucedido das empresas (a competitividade nacional e internacional), pode-se conjecturar que, talvez, o mais adequado seja o procedimento inverso: expandir as tipologias de estratégias de inovação (e de tecnologias) e incorporar

\footnotetext{
31 “Toda classificação de estratégias por tipos tem necessariamente algo de arbitrário e de violência com a infinita variedade de circunstancias do mundo real. $O$ uso de tais tipos ideais pode, entretanto, ser útil para propósitos de conceituação"(...)."Na pratica, existe uma infinita gradação entre tipos" (...) (Freeman e Soete, 1997: 265).

${ }^{32}$ Ver ainda, a este respeito, Coombs (1996) e Marsilli (2001).
} 
a elas as demais estratégias, especialmente nos casos dos setores de elevada intensidade tecnológica.

Supõe-se, ademais, que não se trataria, apenas, de uma mera inversão formal sem outras consequiências. Por razões óbvias, não será possível tratar destas questões no presente artigo. Por isso, limita-se, aqui, a apontar o problema e a propor uma possível abordagem para o mesmo. Em tempo: não nos parece que, por exemplo, 'os objetivos para a estratégia corporativa', propostos por Rothwell (1996: 37), sejam uma solução apropriada para o referido problema.

\section{Considerações finais}

Talvez seja apropriado iniciar estas considerações finais fazendo-se alguns esclarecimentos sobre o que as estratégias não são. Assim, flexibilidade, incrementalidade, adaptabilidade, etc. são atributos/qualidades das estratégias, mas não são equivalentes às mesmas. Neste ponto, uma analogia biológica parece ser útil. As estratégias de reprodução e/ou de alimentação dos organismos vivos são caracterizadas, entre outros atributos, pela maior ou menor flexibilidade (generalidade) e pela maior ou menor adaptabilidade às mudanças ambientais. Estas qualidades não devem, entretanto ser assimiladas às próprias estratégias (Mayr, 2008 e 2009).

De maneira análoga, as estratégias não devem ser confundidas com as táticas, uma vez que elas não são equivalentes e têm, como foi visto (no item V.A., acima), significados e abrangência distintos. Da mesma forma, os objetivos (e/ou as metas) das empresas não devem ser confundidos com as suas estratégias, pelo menos do ponto de vista que vem sendo adotado neste trabalho. Deste ponto de vista, as estratégias se assemelham bastante ao que A. Sloan chamou de 'políticas' das empresas (Whittington, 2002). (Ver, a este respeito, também Simon, 1993 e 1986).

Segundo a perspectiva aqui adotada, as estratégias dizem respeito ao como, ao onde $e$ ao quando fazer e não ao o que fazer. E o como (onde e quando) fazer para a consecução dos objetivos (e/ou metas) envolve a utilização dos meios e das capacidades disponíveis, mas pode implicar também na criação de novos meios e/ou no desenvolvimento de novas capacidades.

Por outro lado, existe uma afinidade e um relativo paralelismo entre a noção de estratégia, segundo a perspectiva adotada neste artigo, e o conceito de inovação proposto por Schumpeter (1984, 1985 e 2005). De fato, uma inovação pode ser uma estratégia e uma estratégia pode implicar em uma ou mais inovações. Ademais, à semelhança das inovações, as chances de uma estratégia ser bem sucedida aumentam a medida em que esta última envolva novidade, surpresa e/ou imprevisto. Reconhecer a ocorrência destas semelhanças não significa, contudo, que se esteja postulando a existência de uma suposta equivalência substantiva entre o conceito schumpeteriano de inovação e a noção de estratégia (ver o subitem II.B., acima). 
Como explicitado anteriormente, as estratégias foram aqui definidas como as decisões relacionadas às grandes questões (os objetivos, ou as metas, principais) das empresas. Estas decisões são tomadas em condições de incerteza radical, sujeitas a racionalidade limitada, em presença de interações (não desprezíveis) entre os agentes, de conflito de interesses e sem garantias de consistência comportamental. As estratégias dizem respeito ao longo prazo e são apenas um subconjunto das chamadas decisões crucias (Shackle, 1976; Davidson, 1996; ver, acima, o subitem V.A.).

Em síntese, é possível afirmar que, da perspectiva aqui adotada, as estratégias podem ser consideradas como o resultado conjunto das expectativas (ver, acima, o subitem IV.B.), da diversidade e da imprecisão - no sentido apontado por Shackle (1976). "A economia converteu verdadeiramente a imprecisão em uma ciência: na ciência da economia, ou da quantificação do inquantificável e da agregação do incompatível" (Schackle, 1976: 378) ${ }^{33}$.

Muito embora não seja, talvez, uma característica tão fundamental e ubíqua na economia como é nas ciências biológicas, a diversidade é, certamente, muito relevante em vários âmbitos/dimensões da primeira, como, por exemplo, nos casos dos processos de tomada de decisão dos agentes econômicos - com os seus múltiplos objetivos, capacidades e comportamentos (Simon, 1986 e 1993; Schumpeter, 1984 e 1994; Shackle, 1976; Freeman e Soete, 1997; Nelson e Winter, 2005; Reinert, 2016; Ziman, 1996 e 2003; Mayr, 2008 e 2009, Gould, 1987).

Deve ser destacada, ainda, a importante relação entre as noções/conceitos de estratégia e de competitividade internacional. De fato, é crescente a percepção, em boa parte da literatura especializada, que a competitividade internacional (C.I.) tem na capacidade de conceber, implementar e adaptar estratégias um dos seus determinantes/condicionantes principais (Simon, 1993; Teece et al., 1997; Rothwell, 1996; Freeman e Soete, 1997; Nelson, 2006; Morroni, 2006; Tidd et al., 2008; Melo et al., 2017).

Talvez não seja de todo ocioso lembrar ao leitor que o tema da competitividade internacional está além do escopo e dos limites impostos a este trabalho e não será, portanto, abordado neste item que fecha o mesmo. Entretanto, talvez seja oportuno informar que, na bibliografia especificamente referida, o leitor interessado encontrará indicações amplas e atualizadas sobre C.I., especialmente no último artigo (Melo et al., 2017), e, em certa medida, sobre a relação entre as noções de estratégia e de C.I..

\footnotetext{
${ }^{33}$ Para uma perspectiva convergente -"a ciência [a economia] imperfeita"-, ver (Hicks, 1980: 9). A respeito da imprecisão categorial nas ciências sociais, na psicologia e na biologia, ver Ziman (1996 e 2003) e, também, Mayr (2008 e 2009).
} 
Para finalizar, deve ser enfatizado que existe, também, uma forte relação -que procurouse mostrar neste artigo- entre as noções de estratégia, de inovações e de concorrência na perspectiva schumpeteriana. Não se trata, é claro, de nenhuma pretensa descoberta deste autor. Trata-se, apenas, de dar o devido destaque a algo que, embora não desconhecido, não recebera ainda - pelo menos até onde alcança o conhecimento destes autores - uma abordagem apropriada (Schumpeter, 1984, 1994, 2005).

\section{Bibliografia}

Ancona, C. (1989a) Tática/estratégia. In: Romano, R. (Dir.) Estado-Guerra. Enciclopédia Einaudi, Vol. 14. Lisboa: Imprensa Nacional.

Ancona, C. (1989b) Guerra. In: Romano, R. (Dir.) Estado-Guerra. Enciclopédia Einaudi, Vol. 14. Lisboa: Imprensa Nacional.

Ansoff, H. I. (1965). Corporate Strategy: An Analytic Approach to Business Policy for Grow and Expansion. New York: McGraw-Hill.

Aron, R. (1986) Paz e guerra entre as nações. Brasília: Edit. da UNB.

Aron, R. (1976). Pensar a Guerra, Clausewitz" (vol. 2). Brasília: Edit. da UNB.

Aron, R. (1986). Pensar a Guerra, Clausewitz" (vol. 1). Brasília: Edit. da UNB.

Arrow, K. J. (1987) Economic Therory and the Hypotesis of Rationality. In: Eatweell, J. et al. The New Palgrave dictionary of economics. Londres: Macmilan.

Arthur, B. W. (1992). On Learning and adaptation in the economy. SFI Working Paper: 92-07-038.

Braybrooke, D. e Lindblom, C. E. (1972). Uma Estratégia de Decisão Social. Rio de Janeiro: Zahar Editores.

Chandler, A. D. Jr. ([1962]1991). Strategy and structure: chapters in the history of the American industrial enterprise. Cambridge: MIT Press.

Clausewitz, C. von (2010) Da Guerra. São Paulo: Martins Fontes.

Basili, M. e Zappia, C. (2010). Ambiguity and Uncertainty in Ellsberg and Shackle. In: Cambridge Journal of Economics, vol. 34, ps. 449-474.

Cyert, R. M. e March, J. G. (1992) A Behavioral Theory of the Firm. Enlewood Cliffs: Prentice-Hall.

Coombs, R. (1996). Technology and business strategy. In: Dodgson e Rothwell (Edits.) The Handbook of Industrial innovation.

Davidison, P. (1982-1983). Rational Expectations: a Fallacious for Studing Crucial Decision-Making Process. In: Journal of Post Keynesian Economics. Vol. 5, No 2, ps. 182-198.

Davidison, P. (1996). Reality and Economic Theory. In: Journal of Post Keynesian Economics. Vol. 18, No 4, ps. 479-508. 
Dodgson, M. e Rothwell, R. (1996). The Handbook of industrial innovation. Cheltenham: Edward Elgar.

Dosi, G. e Malerba F. (1996). Organizational Learning and Istitutional Embeddedness. In: Dosi e Malerba (eds.) Organization and Strategy in the Evolution of the Enterprise. London: Macmillan.

Dosi, G. e Egidi, M. (1991). Substantive and procedural uncertainty: an exploration of economic behaviours in changing environments. In: Journal of Evolutionary Economics, Vol. 1, No 2, ps. 145-168.

Elia, Oscar (2007). Pensar La Guerra, Clausewitz: La Interpretación Aroniana Del Von Kriege. In: Anuario Filosófico, XL/1, ps. 109-127.

Eatwell, J. et al. (Eds.) (1987) The New palgrave dictionary of economics. Londres: Macmilan.

Fagerberg, J. et al. (Eds.) (2005). The Oxford handbook of Innovation. Oxford: OUP.

Fishburn, P. C. (1987) Utility Theory and Decision Theory. In: Eatweell, J. et al. The New Palgrave dictionary of economics. Londres: Macmilan.

Foss, N. J. e Stieglitz, N. (2012). Modern resource-based theory(ies). In: Dietrrich, M. e Krafft, J., Handbook on the economics and theory of the firm. Cheltenham. Edward Elgar.

Freeman, C. e Soete, L. (1997). The Economics of Industrial Innovation. Cambrige: MIT Press.

Georgescu-Roegen, N. (1971). The Entropy law and the economic process. Cambridge: HUP.

Gould, S. J. (1987). La sonrisa del flamenco. Madri: Hermann Blume.

Harvey, M. e Metcalfe, S. (2005). The Ordering of Change: Polanyi, Schumpeter and The Nature of The Market Mechanism. CRIC University of Manchester. Discussion Paper 70.

Heap, S. H. (1998). Game Theory. In: Davis, J. H. et al. (Eds). The Handbook of Economic Methodology. Cheltenham: Edward Elgar.

Heiner, R. A. (1983). The origin of predictable behavior. In: American Economic Review, vol. 73, No 4, ps. 560-95.

Hicks, J. (1980). Causality in economics. Oxford: Basil Blackwell.

Kahneman, D. (2003). Maps of bounded rationality: psychology for behavioral economics. In: American Economic Review, 93(5), ps. 1445-75.

Langlois, R. N. (2003). Strategy as economics versus economics as strategy. In: Managerial and Decision Economics, Vol. 24, ps. 283-290.

Langlois, R. N. e Robertson, P. L. (1995). Firms, markets and economic change: uma teoria dinâmica das instituições de negócios. Londres: Routledge. 
Lindblom, C. E. (1981). O processo de decisão Política. Brasília: Ed. Universidade de Brasília.

Loasby, B. J. (2010). Capabilities and Strategy: problems and prospects. In: Industrial and Corporated Change, Vol. 19, No 4, pp. 1301-1316.

Mahoney, J. T. (2004). Economic Foudations of Strategy. Thousand Oaks: Sage Publications.

Marshall, A. ([1919]2015). Industry and trade: a study of industrial and business organisation; and of their influences on condition of various classes and nations. Nova Delhi: Vani Prakashan.

Marshall, A. ([1920]1985). Princípios de economia. Vol. II . São Paulo: Abril Cultural.

Marsili, O. (2001). The Anatomy and evolution of industries: technological change and industrial dynamics. Cheltenham: Edward Elgar.

Mayr, E. (2008). Isto é biologia: a ciência do mundo vivo. São Paulo: Compahia das Letras.

Mayr, E. (2009). O que é a evolução. Rio de Janeiro: Rocco.

McFadden, D. (1998). Rationality for Economists? Santa Fe Working Paper No 98-09086, ps. 1-38. Reimpresso in: Journal of Risk and Uncertainty, 1999, 19(1-3), ps. 73105.

Melo, T. M., Correa, A. L., Carvalho, E. G. de e Possas, M. L. (2017). Competitividade e Gap Tecnológico - uma análise comparativa entre Brasil e países europeus selecionados. In: Revista Brasileira de Inovação, Vol., 16, Nº 1.

Mintzberg, H. et al. (2006). O Processo da estratégia. Porto Alegre: Bookman

Mintzberg, H. et al. (2000). Safári de estratégia: um roteiro pela selva do planejamento estratégico. Porto Alegre: Bookman.

Morroni, M . (2006). Knowledge, Scale and Transactions in the Theory of the Firm. Cambridge: Cambridge Press.

Nelson, R. R. (2006). As Fontes do crescimento econômico. Campinas: Unicamp.

Nelson, R. R. e Winter, S. G. (2005). Uma teoria evolucionária da mudança econômica. Campinas: Unicamp.

Pavitt, K. (1990). What we know about the strategic management of technology. In: California Management Review, Vol. 32, N² 2, ps. 17-26.

Pavitt, K. e Steinmueller, W. E. (2002). Technology in corporate strategy: change, continuity and the information revolution. In: Pettigrew, A. et al. Handbook of strategy management. Londres: Sage Publications.

Pettigrew, A. et al. (2002). Handbook of strategy management. Londres: Sage Publications. 
Pomian, K. (1993). Tempo/Temporalidade. Vol. 29. Enciclopédia Einaudi. Lisboa. Impressa Nacional.

Popper, K. R (1975). Conhecimento Objetivo: Uma Abordagem Evolucionária. Belo Horizonte: Ed. Itatiaia.

Porter, M. (1980). Competitive Strategy: Techniques for Analyzing industries and Firms. New York: Free Press and Macmillan.

Porter, M. (1996) What is strategy? In: Harvard Business review. Novembro-dezembro, ps. 61-78.

Reinert, E. S. (2016). Como os países ricos ficaram ricos ... e por que os países pobres continuam pobres. Rio de Janeiro: Contraponto.

Rosenberg, N. ([1976]2006). Sobre Expectativas Tecnológicas. In: Rosenberg, N. Por Dentro da Caixa-Preta: tecnologia e economia. Campinas: Unicamp.

Rosenberg, N. (1996). Ucertainty and technological change. In: Landau, R. et al., Mosaic of economic growth. Stanford: Stanford Press.

Rothwell, R. (1996). Industrial innovation: success, strategy, trends. In: Dodgson e Rothwell (Edits.) The Handbook of Industrial innovation. Aldershot: Edward Elgar.

Rumelt, R. P. et al. (1991). Strategic management and economis. In: Strategic Mmanagement Journal, Vol. 12, ps. 5-29.

Schumpeter, J. A. ([1954]1994). History of Economic analysis. Nova York: OUP.

Schumpeter, J. A. ([1935]1985). A Teoria do Desenvolvimento Econômico. São Paulo: Abril Cultural.

Schumpeter, J. A. ([1942]1984). Capitalismo, socialismo e democracia. Rio de Janeiro: Zahar

Schumpeter, J. A. (1968). La Respuesta Creadora en la História Econòmica. In: Ensayos de Joseph A. Schumpeter. Barcelona: Oikos-tau.

Schumpeter, J. A. ([1939]2005). Business cycles: a theoretical, historical, and statistical analysis of the capitalist process V. 1 e 2. Mansfield: Martino Publishing.

Sen, A. K. (1987) Rational Behaviour. In: Eatweell, J. et al. The New Palgrave dictionary of economics. Londres: Macmilan.

Shackle, G. L. S. (1966). Decisión, orden y tiempo em las actividades humanas. Madrid: Tecnos.

Shackle, G. L. S. (1976). Epistemica y Economia: crítica de las Doctrinas Económicas. Cidade do México: Fundo de Cultura Económica.

Simon, H. A. (1993) Strategy and organization evolution. In: Strategic Management Journal, vol.14, ps. 131-142.

Simon, H. A. (1986) Decision Making and problem solving. Report of the research briefing. National Academy of Sciences. 
Simon, H. A (1981). As ciências do Artificial. Coimbra: Armênio Amado.

Simon, H. A. (1978). Rationality as Process and as Product of Thought. In: American Economic Review, Vol. $68 \mathrm{~N}^{\circ}$ 2. Papers and Proceedings of the Ninetieth Annual Meeting of the American Economic Association (maio, 1978), ps. 1-16.

Simon, H. A. (1979). Rational Decision Making in Business Organizations. In: The American Economic Review, Vol. 69 No 4, ps. 493-513.

Simon, H. A (1965). Comportamento Administrativo. Rio de Janeiro: Edit. da Fundação Getúlio Vargas.

Simon, H. A. (1989) A Razão nas coisas humanas. Lisboa: Gradiva.

Teece, D. et al. (1997). Dynamic capabilities and Strategic Management. In: Strategic management Journal, vol. 18, No 7, ps. 509-533.

Teece, D. (2007). Explicating dynamic capabilities: the nature and microfoundations of (sustainable) Enterprise performance. In: Strategic management Journal, vol. 28, ps.1319-50.

Tidd, J. et al. (2008). Gestão da inovação. Porto Alegre: Bookman.

Tversky, A. e Kahneman, D. (1974). Judgment under uncertainty: heuristics and biases. In: Science, 185, ps. 1124-31.

Utterback, J. M. (1996). Dominando a dinâmica da inovação. Rio de Janeiro: Qualitymark Editora.

Vercelli, A. (1999). The recent Advances in Decision Theory Under Uncertainty: a Non-Technical introduction. In: Luini, L. (ed.). Uncertainty Decisions: Bridging Theory and Experiments. Dordrecht: Kluwer.

Whittington, R. (2002). O que é estratégia. São Paulo: Thomson.

Ziman, J. M. (1996). O conhecimento confiável: uma exploração dos fundamentos para a crença na ciência. Campinas: Papirus.

Ziman, J. M. (2003). Qué es la ciencia? Madri: Cambridge University Press. 